\title{
LES ORDALIES
}

\author{
DANS
}

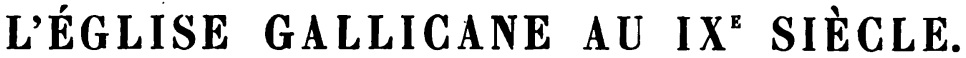

HINGMAR DE REIMS ET SES CONTEMPORAINS.

$$
68311
$$

Il est aujourd'hui bien établi et bien connu que les épreuves judiciaires ou ordalies ne sont propres ni à une coutume ni à une race d'hommes déterminées. On les trouve en effet chez les peuples les plus divers, chez les tribus sauvages des diverses parties du monde, chez les Germains, les Celtes, les Slaves, les Grecs et les Hindous ${ }^{(1)}$. Elles caractérisent un certain degré de civilisation primitive, et apparaissent comme ure des solutions simples qu'ont données les premières sociétés au redoutable problème de la preuve judiciaire. Comment prouver d'une façon adéquate un acte ou un fait contre l'auteur prétendu, qui le nie? Bien souvent encore, après tant de siècles de progrès, la procédure des nations modernes échoue misérablement devant cette difficulté. On comprend aisément que les primitifs fassent alors appel aux dieux, avec lesquels, du reste, ils sont en commerce constant.

Mais il est un milieu dans lequel l'acceptation des ordalies offre un intérêt particulier : c'est la chrétienté occidentale, où clles furent introduites par les invasions des barbares. Elles simposèrent alors à une société qui n'était point primitive. Sans doute, dans la décomposition qui l'envahissait, cette société retournait à la barbarie, reprenait peu à peu des formes inférieures d'organisation sociale : par suite, les conceptions qui correspondent à l'en-

(1) Patetta, Le Ordalie, studio di storia del dirit!o e scienza del diritlo comparato, Torino, 1890 , ch. II-vır.

Scibnces Rbligibuses. -1897 . 